\title{
Parental Responsiveness and Adolescent Susceptibility to Peer Influence: \\ A Cross-Cultural Investigation
}

\author{
ZHIYONG YANG \\ MICHEL LAROCHE*
}

*Zhiyong Yang (yang@uta.edu) is Assistant Professor of Marketing, Department of Marketing, University of Texas at Arlington, Arlington, TX 76019. Michel Laroche (laroche@jmsb.concordia.ca) is Royal Bank Distinguished Professor of Marketing, John Molson School of Business, Concordia University, Montreal, QC H3G 1M8.

The authors are grateful to Ashesh Mukherjee and Charles M. Schaninger for their valuable comments on an earlier version of this paper.

Please direct correspondence to Zhiyong Yang.

Received: August 2009

Accepted: December 2009 


\title{
Parental Responsiveness and Adolescent Susceptibility to Peer Influence: \\ A Cross-Cultural Investigation
}

\begin{abstract}
From a developmental perspective, this research focuses on how parental responsiveness affects adolescent susceptibility to peer influence both directly, and indirectly, through the key elements of adolescent self-concept (i.e., interdependent self-construal, self-esteem, and self-monitoring). Culture is incorporated as a moderator of these effects. The overarching finding in this study is that in individualist cultures such as Canada, responsiveness reduces susceptibility mainly through an indirect effect by undermining interdependent self-construal, fostering self-esteem, and impairing self-monitoring. However, in collectivist cultures such as China, responsive parenting reduces susceptibility primarily through a direct effect. These findings are largely due to the cultural differences in socialization goals oriented toward individualism versus collectivism.
\end{abstract}

Keywords: Parental responsiveness, susceptibility to peer influence, self-construal, self-esteem, self-monitoring, cross-cultural 


\section{Introduction}

Parental responsiveness, defined as the extent to which parents use nurturance, affection, involvement, and support in the child rearing process (Baumrind, 1978), has been viewed as an important socialization means in a family (for a review, see Bogenschneider et al., 1998). Parental responsiveness is especially important for adolescents, because adolescents are at a stage of seeking for independence from their parents while, paradoxically, striving to remain connected to them. At this life stage, emotional connectedness with parents, as fostered by parental responsiveness, plays a more important role in guiding the behaviors of adolescents than physical rules and supervision do (Youniss and Smollar 1985). Acknowledging the important role of parental responsiveness, researchers have associated it with a variety of socialization outcome variables. In consumer research, parental responsiveness has been linked to adolescents' use of influence strategies in family purchases (Bao, Fern, and Sheng, 2007). In public policy and marketing research, parental responsiveness has been associated with adolescents' sexual knowledge, attitudes, and behavior (Moore et al. 2002), and credit card abuse (Palmer, Pinto, and Parente, 2001). In the psychology and public health literatures, parental responsiveness is viewed as an important predictor of undesirable adolescent behaviors such as the adoption of smoking (Windle, 1999; Bogenschneider et al., 1998).

The purpose of this paper is to extend the existing literature to examine the effect of parental responsiveness on an under-examined consumer socialization variable, adolescents' susceptibility to peer influence (SPI), defined as adolescents' tendency to look to standards from peers in developing their own motivations, attitudes, and behavior. Previous studies have clearly established the important role of peer influence in consumer decision making. Susceptibility to interpersonal influence, for example, has been found to be a key factor in shaping consumers' 
attitudes, norms, values and aspirations (Batra, Homer, and Kahle, 2001), affecting product and brand choice (Wooten and Reed 2004), selecting service providers (Keaveney, 1995), and diffusing information regarding new products (Dawar, Parker, and Price, 1996). However, little is known about how parent-child interaction styles, such as parental responsiveness, may affect adolescents' development of SPI.

Peer influence is critical to advance our understanding about adolescent consumers, as adolescence is a stage when individuals are highly susceptible to ideas and trends popular among their peers (Rose, Boush, and Friestad, 1998). A better understanding of the potential impact of parental responsiveness on SPI is important to both marketers and social workers. As Rose (1999) pointed out, parental style is an important segmentation variable. Knowing about the extent to which parents in a family are responsive to their offspring can help marketers distinguish the kids who are highly susceptible to peer influence from those who have low levels of susceptibility. Marketers can then develop different communication strategies to target these groups (e.g., peer-oriented vs. parent-oriented advertisements). Social workers can also use this information to develop parent-oriented educational programs to teach parents to change their parental styles as an approach to help their kids fight against unwanted peer influence. Although we have not seen these programs yet, the important role that parental responsiveness plays in adolescent consumption-related behaviors has been widely acknowledged by marketing practitioners. Social workers, for example, have used advertising to encourage parents to communicate with their teenagers about sex as a way to prevent teens from engaging in risky sexual behavior (Tanner et al., 2008).

Although little research has been conducted to examine how parental responsiveness may affect SPI, previous studies in developmental psychology have shown that responsiveness exerts 
a great deal of impact on adolescents' affiliation to deviant peers (Oxford et al., 2000), reliance on parents vs. peers to solve their personal problems (Bogenschneider et al., 1998), and following their best friend to engage in deviant behaviors such as shoplifting (Fuligni and Eccles 1993). These studies provide a solid foundation for us to explore how parental responsiveness may affect peer influence at a broader level, focusing on the general tendency of adolescents being influenced by peers in purchasing commodities. We further propose that the effects of parental responsiveness are mediated by adolescent self-concept, and moderated by culture. Our focus on self-concept is based on the fact that the adolescent years are a period of self-discovery, a time of transition when children are trying to discover their identity as adults. At this internally precarious time in their lives, self-concept plays an important role in determining adolescents' psychological development and tendency to be influenced by peers.

Culture is often considered the matrix that shapes the nature of interpersonal exchanges in society and provides the context within which parental influences on adolescents are played out (Leung, Lau, and Lam, 1998). Despite the important role of culture in consumer socialization, little research has been conducted to examine the effect of parental responsiveness on adolescents' self-concept or SPI across different cultural contexts. In the present study, we address this gap by focusing on cultural differences in socialization goals between China and Canada, and its implications for the effect of parental responsiveness. Canada is a typical individualist culture that views the self as a unique entity, while China is a typical collectivist culture that views the self as embedded in group memberships (Triandis, 1995). We argue that the overall societal orientation toward individualism or collectivism can moderate the influence of parental responsiveness on adolescent self-concept and SPI. The theoretical framework tested in our study represents a first attempt to examine the antecedents and psychological processes 
underlying adolescent SPI.

\section{Conceptual Framework}

\subsection{Self-Concept}

Self-concept is broadly defined as "conceptions of physical characteristics, typical activities and abilities, relationships and personality traits, and cognitive and emotional qualities" (Hart and Fegley 1997, p. 130). From this definition, we can infer that self-concept is a multifaceted construct that is a result of the developmental interaction between the understanding that adolescents have of themselves and the views about them from social contexts (Oppenheimer, 1990). In this research, we focus on three specific components that relate to the cognitive, affective, and social dimensions of the self-concept, respectively.

Self-construal is the cognitive aspect of self that shows what individuals think about themselves, especially in terms of how self is related to others (Markus and Kitayama 1991). There are two types of self-construal: independent and interdependent. The independent selfconstrual is usually associated with autonomy and separateness of the self from others; in contrast, the interdependent self-construal is associated with connectedness or relatedness of self to others, which involves self-presentations that are blended with representations of others, shared social norms, and flexible interpersonal boundaries (Markus and Kitayama 1991). In any given culture, people simultaneously possess both types of self-construals that differ in availability and accessibility (Gardner, Gabriel, and Lee, 1999). To avoid potential confounding effects caused by the dimensionality of self-construal, the present research only assessed participants' extent to which they construed themselves interdependently. Self-esteem is the affective component of the self that is generally defined in relation to one's feelings of his/her own worthiness and competence (Cooley, 1902). Self-monitoring is the social aspect of self that 
refers to the propensity to monitor and control one's own self-presentation behaviors in order to seek social appropriateness (Snyder, 1974).

A central theme among theories of self-concept is that the self can be influenced by one's social experiences. From an early age, parents provide their children with information about cultural priorities and parental expectations (LeVine et al., 1994). Through extended interaction with their parents, children internalize these inputs, slowly building different aspects of their self-concept. In this process, supportive social experiences, such as responsive parenting, may be especially effective in facilitating transmission of parental values to adolescents. Responsive parenting fosters an emotionally supportive relationship (Peterson and Hann 1999), which is likely to encourage the child to identify with parents and thus absorb their attitudes, values and role expectations. Building on this insight, we now develop specific hypotheses (H1 through H7) about the effects of parental responsiveness on three dimensions self-concept, i.e., interdependent self-construal, self-esteem, and self-monitoring, and the subsequent effects of these dimensions of self-concept on SPI. As presented in Figure 1, H1 to H7 are part of a conceptual model, in which parental responsiveness is specified as the antecedent, three aspects of self as mediators, and culture as the moderator of SPI.

-----Insert Figure 1 about here-----

\subsection{Parental Responsiveness and Adolescent Interdependent Self-Construal}

Little is known about the impact of parental socialization efforts on the development of cognitive self-concept or self-construal, although researchers have argued that the culture one resides in shapes and guides the construction of the type of self-construal that is consistent with the values of the larger society (Yamada and Singelis 1999). The general conception held by cross-cultural researchers is that there is a tendency for individuals in individualist cultures (e.g., 
Canada and the United States) to be more independent, while individuals in collectivist cultures (e.g., China, Korea, and Japan) tend to be more interdependent (Singelis, 1994; Yamada and Singelis 1999). However, this phenomenon only exists at the group level. Significant individual differences in self-construal are found within one culture. While some American adolescents seek more independence (i.e., self-determination) and differentiation (i.e., distinctiveness), others assign more priority to relationships over self-achievements (Escalas and Bettman 2005).

We anticipate that parental responsiveness is negatively related to interdependent selfconstrual for the Canadian adolescents, but positively related to interdependent self-construal for the Chinese adolescents. The rationale is that the interdependent self-construal is consistent with the socialization goals of Chinese society, but not with those of Canadian society. The socialization goals of Chinese society are to train youngsters to get along with others, to conform to the group, and to be well-behaved, while those of Canadian society put emphasis on independence, autonomy, assertiveness, and individuality (Triandis, 1995). However, individuals are not born to voluntarily place the interests of others over their own (an important trait of interdependent self-construal). Responsive parenting, which fosters positive parent-child relationships, makes the intergenerational transmission of such collectivistic norms from parents to their adolescents easier, especially those emphasizing hierarchy in a society, such as obedience to seniors and conformity to authority figures. In line with this reasoning, it has been found that positive parent-adolescent relationships facilitate the identification of adolescents with parental attitudes, values and role expectations and help them incorporate these attitudes into their own value system (Henry, Wilson, and Peterson, 1989). According to Bretherton, Golby and Cho (1997), “making parental values one's own is not the result of identification derived from fear of punishment, but is based on an increasing capacity for self-regulation achieved 
through the supportive quality of parent-child interactions" (p. 104). In contrast, parental responsiveness tends to hinder the development of interdependent self-construal for the Canadians, as it is incongruent with individualistic cultural priorities.

H1a: Parental responsiveness negatively affects Canadian adolescents' interdependent self-construal.

H1b: Parental responsiveness positively affects Chinese adolescents' interdependent self-construal.

\subsection{Parental Responsiveness and Adolescent Self-Esteem}

For both Canadians and Chinese, we expect a positive relationship between parental responsiveness and adolescent self-esteem, but parental influence would be stronger for the Canadians. Responsive parenting behaviors convey information to young people about their worth and instill in children a sense of their inherent value (Openshaw, Thomas, and Rollins, 1984); as a result, adolescent self-esteem is increased. Previous studies examining the effects of responsiveness on self-esteem have consistently found that parental affection or support increases self-esteem in adolescents, whereas failing to receive a sense of parental approval during interactions with their parents decreases it (Hoelter and Harper 1987).

Yet, the strength of this link is expected to be stronger for the Canadian than for the Chinese adolescents. In Western cultures, the development of self is more separate, distinct, and independent of others. Therefore, acceptance and support from parents are sufficient for adolescents to establish a strong positive attitude toward themselves. On the contrary, the Chinese derive their sense of self and self-esteem from their kinship network (Yang, 1981). Their construction of the self emphasizes continuity of family, societal roles, supremacy of hierarchical relationships, compliance with authority and maintenance of stability (Pratt, 1991). Although 
parental interactions are an important contributor to their self-worth, parent-adolescent ties do not account for all social relationships that adolescents use to assess themselves. In other words, while positive feedback from parents can enhance their self-image, their self-esteem is also influenced by other social contacts. Due to the complex collective attributes involved in this selfevaluation process, it is more difficult for Chinese adolescents to precisely evaluate themselves than for their Western counterparts. In this situation, Chinese people tend to devalue rather than overvalue their levels of self-esteem, because self-effacement and modesty are highly valued in Chinese society (Brand, 2004). Such a general propensity to devalue self-esteem should deflate the magnitude of the relationship between responsiveness and self-esteem among Chinese adolescents as well. Therefore,

H2a: In both cultures, parental responsiveness positively affects adolescents' self-esteem.

H2b: The positive impact of parental responsiveness on adolescent self-esteem is stronger for the Canadians than for the Chinese.

\subsection{Parental Responsiveness and Adolescent Self-Monitoring}

Self-monitoring includes both the perspective-taking ability (i.e., to catch the expressive cues of others) and the self-adjustment ability (i.e., to apply those cues to guide one's own expressive behavior). Of these two aspects, the emphasis is on the latter, i.e., the tendency to use the behavior of others or the cues sent by others, rather than one's own personality, as guides to one's behaviors (Snyder, 1974). Few studies have examined the relationships between parenting strategies and self-monitoring. Among the rare exceptions, Eisenberg et al. (1991) found that parental practices that demand children to control their own feelings and negative emotional displays are positively related to their self-monitoring. More recently, a study by Schoenrock et 
al. (1999) showed that high self-monitors are often from families with high levels of conflict and insecurity. A combination of the findings from these two studies seemed to provide support for Graziano and Waschull's (1995) speculation that self-monitoring is a result of parental intolerance or unacceptance of their children' emotional expressions, which can produce distrust of internal cues in these youth and generate poor intergenerational relationships.

Translating these findings into a more general level of parenting, we predict that responsiveness and self-monitoring are negatively associated. A major reason is that parental responsiveness provides a fertile soil to nourish autonomy seeking behaviors of adolescents (Skinner, 1998), including freedom of self-expression and personal dignity. The element of responsive parenting tends to de-emphasize role requirements and situational demands relative to personal preferences in determining how adolescents will behave. Adolescents from these families are likely to pay more attention to their inner needs and feelings than to controlling contingencies, an attribute often found among low self-monitors. In addition, responsiveness normally creates close parent-adolescent relationships, which also seems less likely to foster highly self-monitoring adolescents, as per the findings of Schoenrock et al. (1999).

H3: In both cultures, parental responsiveness negatively impacts adolescents' self-monitoring.

\subsection{Interdependent Self-Construal and SPI}

There is little research in the literature that has examined the relationship between selfconstrual and SPI. We anticipate a positive effect of interdependent self-construal on SPI for both Canadian and Chinese adolescents, but the effect is stronger for the former. Individuals with predominantly interdependent self-construal tend to incorporate the needs of others into their own motivations and behaviors. They are more likely to view themselves from the perspectives 
of others, are highly conscious of group memberships, more vulnerable to criticism and more concerned with the establishment and maintenance of harmonious ties with others (Markus and Kitayama 1991). For those with a strong interdependent self, making decisions based upon their own inner feelings or beliefs may be regarded as immature or selfish; as a result, they are often encouraged to sacrifice personal goals for the good relationship with others (Triandis, 1995). Taken together, the above discussion suggests that adolescents with higher levels of interdependent self-construal are more likely to comply with the expectations of their friends in consumer choices in order to promote interpersonal harmony.

The positive relationship between interdependent self-construal and SPI is expected to be stronger for the Canadian than for the Chinese adolescents. The rationale rests on the significant difference in developmental timetables across cultures. While the formulation of autonomous identity is a primary task of adolescence for Western adolescents, Chinese adolescents are expected to have a prolonged period of dependency on their parents. In particular, Chinese youths exhibit behavioral autonomy substantially later than their Western counterparts (Feldman and Rosenthal 1990). Canadian adolescents, for example, are expected to decide for themselves on a variety of issues, ranging from consumer choices affecting physical appearance to life decisions such as the choice of a boyfriend/girlfriend, marriage, and career. They are also expected to be responsible for any adverse consequences arising from these decisions. In other words, they are literally "free" to be influenced by their peers because they are supposed to be independent decision-makers for all these issues.

Adolescents in collectivistic cultures, however, are not encouraged to make decisions regarding these life events. According to Confucian teaching, it is even immoral for Chinese adolescents to choose a mate or decide a career path without getting prior consent from their 
parents. Parents are required to protect, govern, teach and discipline their children and have the last say in their children's life decisions. As a consequence, when adolescents fail in their life or career, they are normally not the first person blamed; rather, it is their parents who are required by society to take full responsibility for these failures (Ho, 1986). Probably because of this, Chinese parents expect their children to have earlier independence in areas such as task-oriented caretaking activities and academic work, but later in areas such as social and self-initiated tasks (Young, 1972). Forced compliance is socially accepted and self-sacrifice in life decisions is expected from a filial person (Dien, 1999). In such a collectivistic environment, although Chinese adolescents high in interdependent self-construal are willing to sacrifice their personal goals for the good relationship with others, they are less likely to follow the advice of their peers to do things that they perceive their parents may disapprove of. In other words, their loyalty to their parents is so important to them that even if their parents are not physically present, their behaviors will remain strongly influenced by them. When facing peer pressures, the strong consideration of both parental preferences and peer relationships will drive Chinese adolescents to take a "middle-road" choice decision in order to maintain harmony with both parents and peers.

H4a: In both cultures, adolescents' interdependent self-construal positively affects SPI.

H4b: The positive impact of interdependent self-construal on SPI is stronger for the Canadian than for the Chinese adolescents.

\subsection{Self-Esteem and SPI}

We posit a negative association between self-esteem and SPI for both Canadian and Chinese adolescents, but the strength of the association should be stronger for the Canadian ones. 
According to Leary's sociometer theory of self-esteem, self-esteem reflects perceptions of interpersonal inclusion versus exclusion (Leary et al., 1995). Whereas low self-esteem reflects insecurity about interpersonal acceptance, high self-esteem indicates a high level of perceived interpersonal regard. Individuals with low self-esteem report more loneliness than their high selfesteem counterparts, have higher level of social anxiety, and describe themselves as having fewer friends (Leary and Baumeister 2000). They strive to gain the approval of others, a motive that drives them to engage in self-presentation strategies (Brockner, 1988), such as voicing agreement with the views of significant others (Premeaux and Bedeian 2003). Conversely, high self-esteem individuals are more likely to engage in self-esteem reparation at a personal level to reaffirm the self's favorable, individualistic qualities (Leary and Baumeister 2000; Leary et al., 1995), a strategy known as self-protection (Vroom, 1964). One such self-protection strategy is to increase self-ratings of intelligence and derogate others by rating generalized others and even their friends less favorably (Beauregard and Dunning 1998). Similarly, previous studies showed that self-esteem is negatively related to normative interpersonal influence on purchasing decisions (Bearden, Netemeyer, and Teel, 1989) and social comparison in consumption-related issues (Bearden and Rose 1990).

Although such an effect is expected to appear for both Canadian and Chinese adolescents, the strength of this effect is weaker for the latter. When facing peer pressure, high self-esteem Chinese adolescents are less likely to use self-protection strategy; instead, their self-esteem reparation may involve affirming the self through relationships, a similar pattern as their low self-esteem counterparts. According to the Confucian's moralistic conception of the self, the true meaning of self is attained by sacrificing the "little me" to complete the "big me" (Dien, 1983). The use of the self-protection strategy to highlight the "little me" is normally considered as 
selfish and socially unacceptable. Chinese society emphasizes maintaining harmony and following group norms and expectations; hence, the expression of collective attributes of self (i.e., conformity, obedience, and interdependence) is more likely to be valued. Private sense of social-worth in this context is facilitated through the reflected actions and appraisals of others. Therefore, although high self-esteem adolescents do see their own decisions better than their peers', the tendency to maintain harmony may drive them to integrate the opinions of their peers into their purchasing decisions. Peer pressure in this case may heighten their awareness of the dynamic nature of relationships and alert them to pay attention to relationship concord.

H5a: In both cultures, adolescents' self-esteem is negatively related to SPI.

H5b: The negative impact of self-esteem on SPI is stronger for the Canadian than for the Chinese adolescents.

\subsection{Self-Monitoring and SPI}

We expect a positive relationship between self-monitoring and SPI for both cultures. A prototypic high self-monitor has been described as "someone who treats interactions with others as dramatic performances designed to gain attention, make impressions, and at times entertain" (Snyder, 1987, p. 178). They are sensitive to contextual cues and are capable of deliberately modifying their behaviors for the sake of desired public appearances (Premeaux and Bedeian 2003). Particularly, high self-monitors are skilled in reading the nonverbal behavior of others to discern underlying emotions (Geizer, Parick, and Soldow, 1977). They are also more inclined to seek information from others in order to discover the appropriate behavior in a given situation, and to look to situational cues for guidance in how to deliver a desired image (Mill, 1984). In contrast, the expressive behaviors of prototypic low self-monitors tend to reflect their own inner attitudes, emotions and dispositions (Premeaux and Bedeian 2003); consequently, low self- 
monitors are likely to show behavioral consistency across situations and consistency between attitudes and observable actions (Snyder, 1987). Since high self-monitors are effective at social integration and behavior adjustment, compared with low self-monitors, they are more susceptible to interpersonal influence on consumer choices (Bearden, Netemeyer, and Teel, 1990), more vulnerable to pressure from others (Mehra et al., 2001), and more likely to make decisions similar to those with whom they interact socially (Kilduff, 1992).

H6: In both cultures, adolescents' self-monitoring is positively related to SPI.

\subsection{Parental Responsiveness and Adolescent SPI}

We propose a negative relationship between parental responsiveness and adolescents' SPI in both cultures. As discussed before, parental responsiveness fosters close relationships between parents and adolescents. Such a positive parent-child relationship increases the child's motivation and opportunity to share information with parents. This allows parents to become knowledgeable about the child's emotional and physical circumstances and offer timely help when the child needs. Consequently, it is not surprise to see that a child with responsive parents is more likely to deal with peer pressure. Bogenschneider et al. (1998), for instance, found that the level of maternal warmth was inversely related to children's reliance on peers versus parents to deal with personal problems. Nurturant or emotionally supportive relationship encourages the child to identify with parents and incorporate their attitudes, values and role expectations (Henry et al., 1989).

H7: Parental responsiveness is negatively related to SPI for both Canadian and Chinese adolescents.

\section{Method}

\subsection{Sample and Procedure}


The sampling frame consisted of students from four high schools in Ontario, Canada, and six high schools in China. With the help of local district school boards, we recruited teachers to hand out survey packages to students in Grades 8-12. The surveys were completed by the interested students during the regular class time. The Chinese version was a translation of the English survey. The back translation method, in which the survey was first translated from English to Chinese and then back again to English, was applied to ensure the idiomatic equivalence of the Chinese and English versions. We made an additional effort to make sure the translation of the established measurement items was free of linguistic confounds. Specifically, two judges who were not aware of the purpose of this research were recruited to compare the original English and back-translated English versions. The judges agreed that $93 \%$ of items in the two versions conveyed the same meaning. Based on suggestions from the two judges, we made minor modifications on the Chinese version. The final versions were pre-tested with nine Canadian and eight Chinese adolescents to ensure clarity, comprehension and ease of completion.

A total of 1,500 sets of Chinese and 820 sets of English questionnaires were distributed in China and Canada, respectively. In China, 1,289 sets of Chinese surveys were returned, and 40 were excluded because of missing data, yielding a useable response rate of 83.3\%. In Canada, 305 sets of surveys were returned, and 5 were excluded, for a usable response rate of $36.6 \%$. The inequality of the sample sizes is primarily due to a much lower response rate from the Canadian students. Cultural differences in socialization goals can be used to explain this phenomenon, i.e., Chinese students are more submissive to authorities (school teachers in this case). Given that the inequality of sample size increases the likelihood of making Type II errors in invariance tests, we randomly selected 300 responses from the Chinese data set and compared the results with the 
Canadian sample. The results from the Chinese sub-sample largely replicated those of the full sample; therefore, we kept the results of the full sample in the paper. The age profile of the Chinese adolescents $\left(M_{\mathrm{age}}=15.5\right.$ years, ranging from 14 to 18 years $)$ was similar to that of the English-Canadian adolescents $\left(M_{\mathrm{age}}=15.8\right.$ years, with a range of 14 to 18 years $)$. About $14.3 \%$ of the Chinese sample and $22.0 \%$ of the Canadian sample were from single-parent households.

\subsection{Measures}

Independent and mediating variables. Parental responsiveness, the independent variable in our model, was gauged by Paulson's (1994) Responsiveness Scale. Three dimensions of selfconcept, namely interdependent self-construal, self-esteem, and self-monitoring, were potential mediators in our model. Interdependent self-construal was measured with Singelis' (1994) scale; self-esteem was measured by Rosenberg's (1986) Self-Esteem Scale; self-monitoring was assessed by Snyder's (1974) Self-Monitoring Scale.

Dependent variable. The dependent variable of SPI was measured by Bearden et al.'s (1989) 8-item scale of consumer susceptibility to normative influence, which is a broad measure of interpersonal influence on consumption-related issues. The wording of some items was tailored to peer influence among adolescent respondents. This adapted version was used by Zhang (2001) to assess Chinese adolescents' SPI and found to be reliable. With the exception of demographic measures, all items in the questionnaire were assessed with 5-point scales.

\subsection{Analysis and Results}

Given that the focus of this study was to test the moderating effects of culture on the proposed relationships among parental responsiveness, self-concept, and SPI, it was important to ensure the equivalence of the measurement model across the Canadian and Chinese groups (cf. Steenkamp and Baumgartner 1998). Following the procedures suggested by Kim and Lee (1997), 
we purified the items and confirmed a similar factor pattern across the Chinese and the Canadian samples. Factor analysis on the combined sample using the final set of purified items (see Appendix) yielded five distinct factors (i.e., paternal responsiveness, interdependent selfconstrual, self-esteem, self-monitoring, and SPI), which jointly explained $70.3 \%$ of the variance in our data. The extracted factors had adequate reliabilities, with all Cronbach's alphas above the 0.70 threshold (Nunnally, 1978). Subsequent analyses on separate samples (i.e., Chinese, Canadian) also confirmed the factor structure and the reliability of the measures.

Measurement model. Before testing the full latent model, the EQS software of Bentler (1992) was used to perform a CFA on the measurement model for each sample. Estimation displayed desirable goodness of fit statistics for our data, as indicated by $\chi^{2}(265)=387.2, \chi^{2} / \mathrm{df}=$ $1.46, p=.000, \mathrm{CFI}=.93, \mathrm{RMSEA}=.047$ for the Chinese sample, and $\chi^{2}(265)=298.1, \chi^{2} / \mathrm{df}=$ $1.12, p=.010, \mathrm{CFI}=.98, \mathrm{RMSEA}=.032$ for the Canadian sample. We then assessed convergent and discriminant validity of these factors for each sample. Evidence of the former relates to the extent to which items correlate strongly with other items used to measure the same construct, while the latter refers to the degree to which measures of different constructs are unique from each other (Churchill, 1979). According to Fornell and Larcker (1981), convergent validity is established if the average variance extracted for each factor accounts for 0.50 or more of the total variance. The results confirmed convergent validity of these factors extracted from our data in both groups, with the average variance extracted for the factors were all above the 0.50 cut-off value, ranging from .503 to .572 in the Chinese sample, and from .509 to .637 in the Canadian sample. Moreover, Anderson and Gerbing (1988) note that convergent validity is demonstrated by statistically significant path coefficients. In this study, all coefficients were significant at the $p$ $<.05$ level. 
Discriminant validity is established if the average variance extracted is larger than the squared correlation coefficients between factors (Fornell and Larcker 1981). The results showed that this criterion was met across all pairs of factors. Furthermore, results from LaGrange Multiplier (LM) tests indicated no significant cross-loadings for measurement items with nonhypothesized constructs thus providing additional evidence to support the discriminant validity of these constructs.

Testing hypotheses H1 through H7. A two-step analysis was conducted to test hypotheses H1 through H7. In the first step, the full latent model (see Figure 1) was specified separately for the Canadian and the Chinese samples and treated as the baseline for subsequent cross-cultural comparison analyses. Estimation of these two baseline structural models generated acceptable fit (Chinese: $\chi^{2}=390.1, \mathrm{df}=268, \chi^{2} / \mathrm{df}=1.46, p=.000, \mathrm{CFI}=.93, \mathrm{RMSEA}=.047$; Canadian: $\chi^{2}=$ $\left.300.1, \mathrm{df}=268, \chi^{2} / \mathrm{df}=1.12, p=.010, \mathrm{CFI}=.98, \mathrm{RMSEA}=.032\right)$. In the second step, we introduced measurement-level constraints - namely configural invariance, metric invariance, factor covariance invariance, and error variance invariance - to simultaneously test the equivalence of these two models. Through a series of model comparisons, we found that the five factors had the same factor patterns, factor structure, and factor covariances across the two samples. As shown in Table 1, the measurement invariance model fitted the data well, with $\chi^{2}=$ 722.6, $\mathrm{df}=536, p=.001, \chi^{2} / \mathrm{df}=1.35$, and $\mathrm{CFI}=.95$.

-----Insert Table 1 about here-----

Hypotheses $\mathrm{H} 1 \mathrm{a}$ and $\mathrm{H} 1 \mathrm{~b}$, respectively, predicted that parental responsiveness would be negatively associated with adolescent interdependent self-construal for the Canadians, whereas the reverse would be true for the Chinese. Consistent with these hypotheses, responsiveness was found to be negatively related to interdependent self-construal in the Canadian model $(b=-.307$, 
$t=-3.14, p<.01)$, but positively related to interdependent self-construal in the Chinese model $(b$ $=.277, t=6.52, p<.001)$. Therefore, $\mathrm{H} 1 \mathrm{a}$ and $\mathrm{H} 1 \mathrm{~b}$ were supported. $\mathrm{H} 2$ specified that parental responsiveness would be positively related to self-esteem in both cultures (H2a), but the effect would be stronger for the Canadians ( $\mathrm{H} 2 \mathrm{~b})$. Consistent with $\mathrm{H} 2 \mathrm{a}$, responsiveness had a positive link with self-esteem in both the Canadian model $(b=.405, t=5.90, p<.001)$ and the Chinese model $(b=.266, t=6.60, p<.001)$. Further, results of the invariance test showed that the estimate in the Chinese model was significantly lower than that in the Canadian model ( $b_{\text {Canadian }}$ $=.405$ vs. $\left.b_{\text {Chinese }}=.266, \chi^{2}=4.02, p<.05\right)$, lending support for $\mathrm{H} 2 \mathrm{~b} . \mathrm{H} 3$ posited a negative relationship between responsiveness and self-monitoring in both cultures. As expected, a negative link between responsiveness and self-monitoring was found in the Canadian model $(b=$ $-.177, t=-2.27, p<.05)$; however, this link was not significant in the Chinese model $(p>.10)$. Therefore, H3 was partially supported.

H4a suggested a positive association between interdependent self-construal and SPI in both cultures, and $\mathrm{H} 4 \mathrm{~b}$ proposed that the strength of this link is stronger for the Canadians. Consistent with $\mathrm{H} 4 \mathrm{a}$, interdependent self-construal was positively related to SPI for the Canadians $(b=.389, t=3.82, p<.001)$. Nonetheless, no such relationship was found for the Chinese $(p>.10)$. Therefore, H4a was partially supported. Follow-up invariance tests indicated that the positive association between interdependent self-construal and SPI was stronger for the Canadians than for the Chinese $\left(b_{\text {Canadian }}=.389\right.$ vs. $\left.b_{\text {Chinese }}=-.059, \chi^{2}=16.87, p<.001\right)$, lending support for H4b. In H5a, it was expected that self-esteem would be negatively related to SPI for both Canadians and Chinese, whereas $\mathrm{H} 5 \mathrm{~b}$ posited that such a negative association would be stronger for the Canadians. Results showed a negative link between self-esteem and SPI in the Canadian model $(b=-.167, t=2.01, p<.05)$, but not in the Chinese one $(p>.10)$. The 
difference in the magnitude of these two estimates was statistically significant $\left(b_{\text {Canadian }}=-.167\right.$ vs. $\left.b_{\text {Chinese }}=.110, \chi^{2}=6.28, p<.01\right)$. These results lent partial support for H5a and full support for H5b. H6 posited a positive association between self-monitoring and SPI in both cultures. As expected, self-monitoring was found to be positively related to SPI in both the Canadian model $(b=.253, t=3.00, p<.01)$ and the Chinese one $(b=.261, t=6.69, p<.001)$, supporting H6. In H7, we anticipated a negative association between parental responsiveness and SPI in both cultures. Results showed that parental responsiveness was negatively related to SPI for the Chinese $(b=-.199, t=-2.45, p<.05)$, but not for the Canadians $(p>.10)$, although the estimate in the Canadian model was in the hypothesized direction. Thus, H7 was partially supported.

Relative contributions of self-concept. To examine the important role of including the three aspects of self-concept as the mediating variables in the model, we compared the proposed model to a direct-effect model (with only parental responsiveness as predictor; three self-concept variables omitted as mediators) in terms of $\mathrm{R}^{2}$ adjusted, using Cohen's (1988) formula for calculating effect size $\left(\mathrm{f}^{2}\right)$ (the degree to which the phenomenon is present in the population):

$$
\mathrm{f}^{2}=\left(\mathrm{R}_{\text {included }}^{2}-\mathrm{R}_{\text {excluded }}^{2} /\left(1-\mathrm{R}_{\text {included }}^{2}\right)\right.
$$

Results showed that dropping self-concept from the model significantly reduces the variance explained in SPI to $\mathrm{R}^{2}=.182\left(\mathrm{f}^{2}=.43\right)$ for the Canadian model and to $\mathrm{R}^{2}=.117\left(\mathrm{f}^{2}=.09\right)$ for the Chinese model. In addition, the direct-effect model without self-concept variables has significantly lower predictive validity compared to the proposed model, as shown by the substantial effect sizes (Cohen, 1988). This was especially true for the Canadian model. A further analysis on the total effects, indirect effects, and direct effects of parental responsiveness on SPI using the Sobel (1987) approach showed that more than $83.1 \%$ of parental responsiveness' total effect on SPI flows through self-concept in the Canadian model, whereas 
$20.5 \%$ of its total effect on SPI was mediated by self-concept in the Chinese model. These results suggest important cultural differences in the effect of parental responsiveness on SPI. Specifically, the impact of responsiveness on the Canadian adolescents' SPI works primarily through the mediating mechanism of self-concept, but its impact on the Chinese adolescents' SPI works mainly through the direct path.

\section{General Discussion \& Future Research}

Adolescents are often susceptible to the opinions of peers, such as their friends, activity partners and co-workers. Marketing practitioners have recognized the importance of peer influence when targeting adolescent consumers, by emphasizing interpersonal communications such as buzz marketing and opinion leaders (Kotler, Armstrong, and Cunningham, 2005). And every year, marketers in North America spend over a billion dollars on advertising in youthoriented channels including television advertising, in-school marketing, product placements, and children's clubs (Austin and Reed 1999). In this study, we develop and test an integrative model of adolescent susceptibility to peer influence (SPI) that includes parental responsiveness as driver, adolescents' self-concept as mediator, and the cultural context as moderator of SPI. Our model simultaneously tests both direct effects of parental responsiveness on SPI, as well as its indirect effects through aspects of self-concept. We validate our model using respondents from two cultures. Our model makes a number of important theoretical contributions, outlined below, to the literature on family influences in decision making.

Our primary and overarching finding is that in a western cultural context, responsive parenting reduces SPI by influencing adolescents' self-concept. The intuition underlying this result may be traced back to a shift in child-rearing norms in western cultures over the last fifty years. Beginning with Baumrind's (1968) seminal work on parenting, most western cultures have 
moved towards a model of childrearing that emphasizes the social values of individualism and autonomy. As a result, responsive parenting in a western cultural context serves to create relatively self-oriented adolescents, who are thereby better equipped to distance themselves from peer pressure. In the current research, we show that this shift has been socially beneficial in at least one major way - it has served to decrease adolescent SPI by modifying key elements of their self-concept. In particular, we show that responsiveness reduces SPI by undermining interdependent self-construal, fostering self-esteem, and impairing self-monitoring. These results provide a deeper understanding of the impact of parental responsiveness on SPI, and the internal psychological processes in adolescents that mediate these effects.

Our second major finding is that the cultural context can moderate the impact of parenting on SPI. Parental responsiveness tends to foster adolescents' interdependent selfconstrual in China but to undermine the development of the interdependent self in Canada. A higher level of interdependent self-construal, yet, increases the Canadians' but not the Chinese's SPI. In addition, responsiveness has a stronger influence on adolescent self-esteem in Canadian society than in Chinese society. Armed with a higher level of self-esteem, Canadian adolescents are less susceptible to peer influence; however, this is not the case for Chinese adolescents. These cross-cultural differences can be largely attributed to the unique characteristics and priorities of each society.

Our results also have substantive implications for managers and parents. From a managerial perspective, our results suggest that marketers should allocate larger budgets for interpersonal communications, such as buzz marketing and opinion leaders, when targeting adolescent consumers in western cultures such as Canada or United States, as compared to more eastern cultures such as China and Japan. In eastern cultures, it may be more profitable to 
influence parents, who would in turn influence their adolescents. Furthermore, within each culture, parental responsiveness can be a meaningful segmentation variable to identify adolescents who are high or low in susceptibility to peer influence from peers. It is acknowledged in consumer research that parental styles are important segmentation variables. Rose (1999), for example, concludes that a deeper understanding of parental styles helps managers "assess the overlap and specific types of parental styles across nations to determine the effectiveness and likely reaction of parents to various products and promotions" (p. 118).

One issue not examined in depth in the present research was the potential difference in the effects of paternal and maternal childrearing practices. Previous research suggests that mothers are more responsive than fathers (Shek, 2000). But we do not know much about how paternal responsiveness and maternal responsiveness may affect adolescents differently. Future researchers should measure fathers' and mothers' parental responsiveness separately to examine the disparities in the functions of paternal and maternal parenting behaviors on adolescent selfdevelopment and SPI. In addition, the inequality of the sample sizes is a limitation and future research should collect more data from Canada to increase the generalizability of the findings. 


\section{APPENDIX \\ SCALE ITEMS USED IN THE MODEL}

\begin{tabular}{|c|c|c|c|}
\hline \multirow{2}{*}{ Scale Items } & \multicolumn{3}{|c|}{ Cronbach's $\alpha$} \\
\hline & Combined & Canadian & Chinese \\
\hline $\begin{array}{l}\text { Parental Responsiveness (RES) } \\
\text { 1. My parents encourage me to talk with them about things. } \\
\text { 2. My parents expect me to tell them when I think a rule is unfair. } \\
\text { 3. My parents encourage me to look at both sides of an issue. } \\
\text { 4. My parents take my ideas seriously, when making family decisions. } \\
\text { 5. My parents talk it over and reason with me when I misbehave. } \\
\text { 6. My parents respect my opinion and encourage me to express it. } \\
\text { 7. My parents praise me if I do things well. }\end{array}$ & .83 & .83 & .81 \\
\hline $\begin{array}{l}\text { Self-Esteem (ESTEEM) } \\
\text { 1. I take a positive attitude toward myself. } \\
\text { 2. I feel I am a person of worth, at least on an equal plane with others. } \\
\text { 3. I am able to do things as well as most other people. } \\
\text { 4. On the whole, I am satisfied with myself. }\end{array}$ & .79 & .80 & .71 \\
\hline $\begin{array}{l}\text { Interdependent Self-Construal (INTER) } \\
\text { 1. My relationships with other people are more important to me than my own } \\
\text { accomplishments. } \\
\text { 2. It is usually better to work with others than to work alone, even if they aren't as good at } \\
\text { things as I am. } \\
\text { 3. Blending in is better than standing out. } \\
\text { 4. It is important to me to follow the decisions made by the group. }\end{array}$ & .77 & .70 & .81 \\
\hline $\begin{array}{l}\text { Self-Monitoring (SMONI) } \\
\text { 1. In different situations with different people, I often act like very different people. } \\
\text { 2. I can look anyone in the eye and tell a lie with a straight face (if for a right end). } \\
\text { 3. I am not always the person I appear to be. } \\
\text { 4. I can change my behavior depending on who is around. }\end{array}$ & .72 & .72 & .70 \\
\hline $\begin{array}{l}\text { Susceptibility to peer influence (SPI) } \\
\text { 1. It is important that my friends like the products and brands I buy. } \\
\text { 2. If I want to be like someone, I often try to buy the same products or brands that they buy. } \\
\text { 3. I would like to purchase products and brands my friends will approve of. } \\
\text { 4. To maintain a good relationship with friends, I often purchase the same products or brands } \\
\text { they purchase. } \\
\text { 5. I feel that the purchase or use of a particular brand will enhance my image. } \\
\text { 6. I feel that purchase or use of a particular brand helps me show my friends who I am, or } \\
\text { would like to be (such as an athlete, successful businessman, etc.). }\end{array}$ & .83 & .73 & .75 \\
\hline
\end{tabular}




\section{REFERENCES}

Anderson J, Gerbing D. Structural Equation Modeling in Practice: A Review and Recommended Two Step Approach. Psychol Bull 1992;103(May):411-23.

Austin MJ, Reed ML. Targeting Children Online: Internet Advertising Ethics Issues. J Consum Mark 1999;16(6):590-602.

Bao Y, Fern EF, Sheng S. Parental Style and Adolescent Influence in Family Consumption Decisions: An Integrative Approach. J Bus Res 2007;60:672-680.

Batra R, Homer PM, Khale LR. Values, Susceptibility to Normative Influence, and Attribute Importance Weights: A Nomological Analysis. J Consum Psychol 2001;11(2):115-128.

Baumrind D. Authoritarian vs. Authoritative Parental Control. Adolescence 1968;3(Fall):255272.

Baumrind D. Parental Disciplinary Patterns and Societal Competence in Children. Youth and Society 1978;9(March):239-276.

Beauregard KS, Dunning D. Turning Up the Contrast: Self-enhancement Motives Prompt Egocentric Contrast Effects in Social Judgments. J Personality Social Psychol 1998;74:606-621.

Bearden WO, Netemeyer RG, Teel JE. Measurement of Consumer Susceptibility to Interpersonal Influence. J Consum Res 1989;15(March):473-481.

Bearden WO, Netemeyer RG, Teel JE. Further Validation of the Consumer Susceptibility to Interpersonal Influence Scale. Advances Consum Res 1990;17:770-776.

Bearden WO, Rose RL. Attention to Social Comparison Information: An Individual Difference Factor Affecting Consumer Conformity. J Consum Res 1990;16(March):461-471.

Bentler P. EQS Structural Equations Program Manual. Los Angeles, CA: BMDP, 1992. Bogenschneider K, Wu M-Y, Raffaelli M, Tsay JC. Parent Influences on Adolescent Peer Orientation and Substance Use: The Interface of Parenting Practices and Values. Child Development 1998;69(6):1672-1688.

Brand M. Collectivistic versus Individualistic Cultures: A Comparison of American, Australian and Chinese Music Education Students' Self-esteem. Music Education Research 2004;6(1):57-66.

Bretherton I, Golby B, Cho E. Attachment and the Transmission of Values. In Parenting and Children's Internalization of Values: A Handbook of Contemporary Theory, L Kuczynski (Ed.), New York: Wiley, 1997.

Brockner J. Self-Esteem at Work: Research, Theory, and Practice, Lexington, MA: Lexington, 1988.

Churchill G. A Paradigm for Constructing Better Measures of Marketing Concepts. J Mark Res 1979;16(1):64-73.

Cohen, J. Statistical Power Analysis for the Behavioral Sciences. Hillsdale, NJ: Erlbaum, 1988.

Cooley CH. Human Nature and the Social Order. New York: Scribner's, 1902.

Dawar N, Parker PM, Price LJ. A Cross-Cultural Study of Interpersonal Information Exchange. $J$ Internat Bus Stud 1996;3:497-514.

Dien DS. Big Me and Little Me: A Chinese Perspective on Self. Psychiatry 1983;46:281-286.

Dien DS. Chinese Authority-Directed Orientation and Japanese Peer-group Orientation:

Questioning the Notion of Collectivism. Rev General Psychol 1999;3:372-385.

Eisenberg N, Fabes RA, Schaller M, Carlo G, Miller PA. The Relations of Parental Characteristics and Practices to Children's Vicarious Emotional Responding. Child 
Development 1991;62:1393-1408.

Escalas JE, Bettman JR. Self-Construal, Reference Groups, and Brand Meaning. J Consum Res 2005;32(3):378-389.

Feldman SS, Rosenthal DA. The Acculturation of Autonomy Expectations in Chinese High Scholars Residing in Two Western Nations. Internat J Psychol 1990;25(3):259-281.

Fuligni AJ, Eccles JS. Perceived Parent-Child Relationships and Early adolescents' Orientation towards Peers. Developmental Psychol 1993;29:622-632.

Fornell C, Larcker DF. Evaluating Structural Equation Models with Unobservable Variables and Measurement Error. J Mark Res 1981;18(1):39-50.

Gardner WL, Gabriel S, Lee AY. 'I' Value Freedom but 'We' Value Relationships: SelfConstrual Priming Mirrors Cultural Differences in Judgment. Psychol Sci 1999;10:321326.

Geizer RS, Parick DC, Soldow GF. Deception and Judgment Accuracy: A Study in Person Perception. Personal Soc Psychol Bull 1977;3:467-482.

Graziano WG, Waschull SB. Social Development and Self-Monitoring. In Social Development, N Eisenberg (Ed.), Thousand Oaks, CA: Sage, 1995,pp.233-260.

Hart D, Fegley S. The Development of Self-Awareness and Self-Understanding in Cultural Context. In Culture, Experience, and the Conceptual Self, U Neisser, DA Jopling (Eds.), New York: Cambridge, 1997,pp.128-153.

Henry CS, Wilson SM, Peterson GW. Parental Competence Bases and Processes as Predictors of Adolescent Conformity. J Adolescent Res 1989;4:15-32.

Ho DYF. Chinese Pattern of Socialization: A Critical Review. In The Psychology of the Chinese People, MH Bond (Ed.), New York: Oxford, 1986,pp.1-37.

Hoelter J, Harper L. Structural and Interpersonal Family Influences on Adolescent Self-Concept. J Marriage Family 1987;49:129-139.

Keaveney SM. Customer Switching Behavior in Service Industries: An Exploratory Study. $J$ Mark 1995;59(April):71-82.

Kilduff M. The Friendship Network as A Decision-Making Resource: Dispositional Moderators of Social Influences on Organizational Choice. J Personality Soc Psychol 1992;62:168-80.

Kim C, Lee H. Development of Family Triadic Measures for Children's Purchase Influence. $J$ Mark Res 1997;34(3):307-321.

Kotler P, Armstrong G, Cunningham PH. Principles of Marketing, Toronto: Prentice Hall, 2005. Leary MR, Tambor ES, Terdal SK, Downs DL. Self-Esteem as an Interpersonal Monitor: The Sociometer Hypothesis. J Personality Soc Psychol 1995;68:518-530.

Leary MR, Baumeister RF. The Nature and Function of Self-Esteem: Sociometer Theory. In Advances in Experimental Social Psychology 32, MP Zanna (Ed.), New York: Academic, 2000,pp.1-62.

Leung K, Lau S, Lam W-L. Parenting Styles and Academic Achievement: A Cross-Cultural Study. Merrill-Palmer Quarterly 1998;44:157-172.

LeVine RA, Levine S, Dixon S, Richman A, Leiderman PH, Keefer CH, Braxelton TB. Childcare and Culture: Lessons from Africa. New York: Cambridge, 1994.

Markus HR, Kitayama S. Culture and The Self: Implications For Cognition, Emotion, and Motivation. Psychol Review 1991;98:224-253.

Mehra A, Kilduff M, Brass DJ. The Social Networks Of High and Low Self-Monitors: Implications for Workplace Performance. Admin Sci Quart 2001;46:121-146.

Mill J. High and Low Self-Monitoring Individuals: Their Decoding Skills and Empathic 
Expression. J Personality 1984;52(4):372-388.

Moore JN, Raymond MA, Mittelstaedt JD, Tanner JF Jr. Age and Consumer Socialization Agent Influences on Adolescents' Sexual Knowledge, Attitudes, and Behavior: Implications for Social Marketing Initiatives and Public Policy. J Public Policy Mark 2002;21(1):37-52. Nunnally JC. Psychometric Theory. New York: McGraw-Hill, 1978.

Openshaw DK, Thomas DL, Rollins BC. Parental Influences on Adolescent Self-Esteem. J Early Adolescence 1984;4:259-274.

Oppenheimer L. The Self-Concept: European Perspectives on Its Development, Aspects and Applications. New York: Springer Verlag, 1990.

Oxford ML, Harachi TW, Catalano RF, Abbott RD. Preadolescent Predictors of Substance Initiation: A Test of Both the Direct and Mediated Effects of Family Social Control Factors on Deviant Peer Associations and Substance Initiation. American J Drug Alcohol Abuse 2000;27(4):599-616.

Palmer TS, Pinto MB, Parente DH. College Students' Credit Card Debt and the Role of Parental Involvement: Implications for Public Policy. J Public Policy Mark 2001;20(1):105-113.

Paulson SE. Relations of Parenting Style and Parental Involvement with Students' Achievement. J Early Adolescence 1994;14(2):250-267.

Peterson GW, Hann D. Socializing Parents and Children in Families. In Handbook of Marriage and the Family, M Sussman, S Steinmetz, GW Peterson (Eds.), New York: Plenum, 1999,pp.327-370.

Pratt DD. Conceptions of self within China and the United States. Internat J Intercultural Relations 1991;15:285-310.

Premeaux SF, Bedeian AG. Breaking the Silence: The Moderating Effects of Self-Monitoring in Predicting Speaking Up in the Workplace. J Manage Stud 2003;40(6):1537-1562.

Rose GM. Consumer Socialization, Parental Style, and Development Timetables in the United States and Japan. J Mark 1999;63(July):105-119.

Rose GM, Boush D, Friestad M. Self-Esteem, Susceptibility to Interpersonal Influence, and Fashion Attribute Preference in Early Adolescents. European Adv Consum Res 1998;3:197203.

Rosenberg M. Conceiving the Self. Florida: Krieger, 1986.

Schoenrock CJ, Bell NJ, Sun S-W, Avery AW. Family Correlates of Adolescent Self-Monitoring and Social Competence. J Psychol 1999;133(4):377-393.

Shek DTL. Differences between Fathers and Mothers in the treatment of and Relationship with Their Teenage Children: Perceptions of Chinese Adolescents. Adolescence 2000;35(Spring):135-146.

Singelis TM. The Measurement of Independent and Interdependent Self-Construals. Personality Soc Psychol Bull 1994;20(5):580-591.

Snyder M. Self-Monitoring of Expressive Behavior. J Personality Soc Psychol 1974;30(4):526537.

Snyder M. Public Appearances/Private Realities: The Psychology of Self-Monitoring. New York: Freeman, 1987.

Skinner EA. Commentary: Strategies for Studying Social Influences on Motivation. In Motivation and Self-regulation across the Life-span, J Heckhausen, CS Dewck (Eds.), New York, NY: Cambridge, 1998,pp.216-234.

Sobel ME. Direct and Indirect Effects in Linear Structural Equation Models, Sociological Methods Res 1987;16(1):155-176. 
Steenkamp JBEM, Baumgartner H. Assessing Measurement Invariance in Cross-National Consumer Research. J Consum Res 1998;25(June):78-90.

Tanner JF, Carlson LA, Raymond MA, Hopkins, CD. Reaching Parents to Prevent Adolescent Risky Behavior: Examining the Effects of Threat Portrayal and Parenting Orientation on Parental Participation Perceptions. J Public Policy Mark 2008;27(2):149-155.

Triandis HC. Individualism and Collectivism, Boulder, CO: Westview, 1995.

Vroom V. Work and Motivation. New York: Wiley, 1964.

Windle MT. Alcohol Use Among Adolescents. Thousand Oaks, CA: Sage, 1999.

Wooten DB, Reed A. Playing It Safe: Susceptibility to Normative Influence and Protective SelfPresentation. J Consum Res 2004;31(December):551-556.

Yamada AM, Singelis TM. Biculturalism and Self-construal. Internat J Intercultural Relations 1999;23:697-709.

Yang KS. Social Orientation and Modernity among Chinese Students in Taiwan. J Soc Psychol 1981;113(2):159-170.

Young NF. Independence Training from a Cross-Cultural Perspective. American Anthropologist 1972;74(3):629-638.

Youniss J, Smollar J. Adolescent Relations with Mothers, Fathers, and Friends. Chicago: Chicago, 1985.

Zhang M. Differences in Susceptibility to Interpersonal Influence - Chinese s-generation Adolescents and Older Adults. Unpublished Thesis, ON: Guelph, 2001. 
TABLE 1

DIFFERENCES BETWEEN CANADIAN AND CHINESE MODELS

\begin{tabular}{|c|c|c|c|c|}
\hline \multirow{2}{*}{$\begin{array}{l}\text { Causal paths } \\
\text { in the parent-self-peer model }{ }^{\mathrm{a}}\end{array}$} & \multicolumn{2}{|c|}{ Standardized $\beta$ values ${ }^{\mathrm{c}}$} & \multirow[b]{2}{*}{ Chi-square } & \multirow[b]{2}{*}{ p-value } \\
\hline & $\begin{array}{l}\text { Canadians } \\
(\mathrm{N}=300)\end{array}$ & $\begin{array}{c}\text { Chinese } \\
(\mathrm{N}=1,249)\end{array}$ & & \\
\hline RES $\rightarrow$ INTER (H1a, H1b) & $-.307^{* *}$ & $.277^{* * *}$ & 26.11 & .000 \\
\hline $\mathrm{RES} \rightarrow \operatorname{ESTEEM}(\mathrm{H} 2 \mathrm{a}, \mathrm{H} 2 \mathrm{~b})$ & $.405^{* * *}$ & $.266^{* * *}$ & 4.02 & .045 \\
\hline $\mathrm{RES} \rightarrow \mathrm{SMONI}(\mathrm{H} 3)$ & $-.177^{*}$ & -.043 & 3.25 & .071 \\
\hline $\mathrm{INTER} \rightarrow \mathrm{SPI}(\mathrm{H} 4 \mathrm{a}, \mathrm{H} 4 \mathrm{~b})$ & $.389^{* * * *}$ & -.059 & 16.87 & .000 \\
\hline ESTEEM $\rightarrow$ SPI (H5a, H5b) & $-.167^{*}$ & .110 & 8.28 & .004 \\
\hline $\mathrm{SMONI} \rightarrow \mathrm{SPI}(\mathrm{H} 6)$ & $.253^{* *}$ & $.261^{* * *}$ & 1.09 & .296 \\
\hline $\mathrm{RES} \rightarrow \mathrm{SPI}(\mathrm{H} 7)$ & -.032 & $-.199^{*}$ & 4.71 & .030 \\
\hline Variance explained in SPI & $42.9 \%$ & $18.8 \%$ & & \\
\hline Fit indices of the invariance test & \multicolumn{4}{|c|}{$\chi^{2}=722.6, \mathrm{df}=536, \chi^{2} / \mathrm{df}=1.35, p=.000, \mathrm{CFI}=.95$} \\
\hline
\end{tabular}


FIGURE 1

THE PARENT-SELF-PEER MODEL

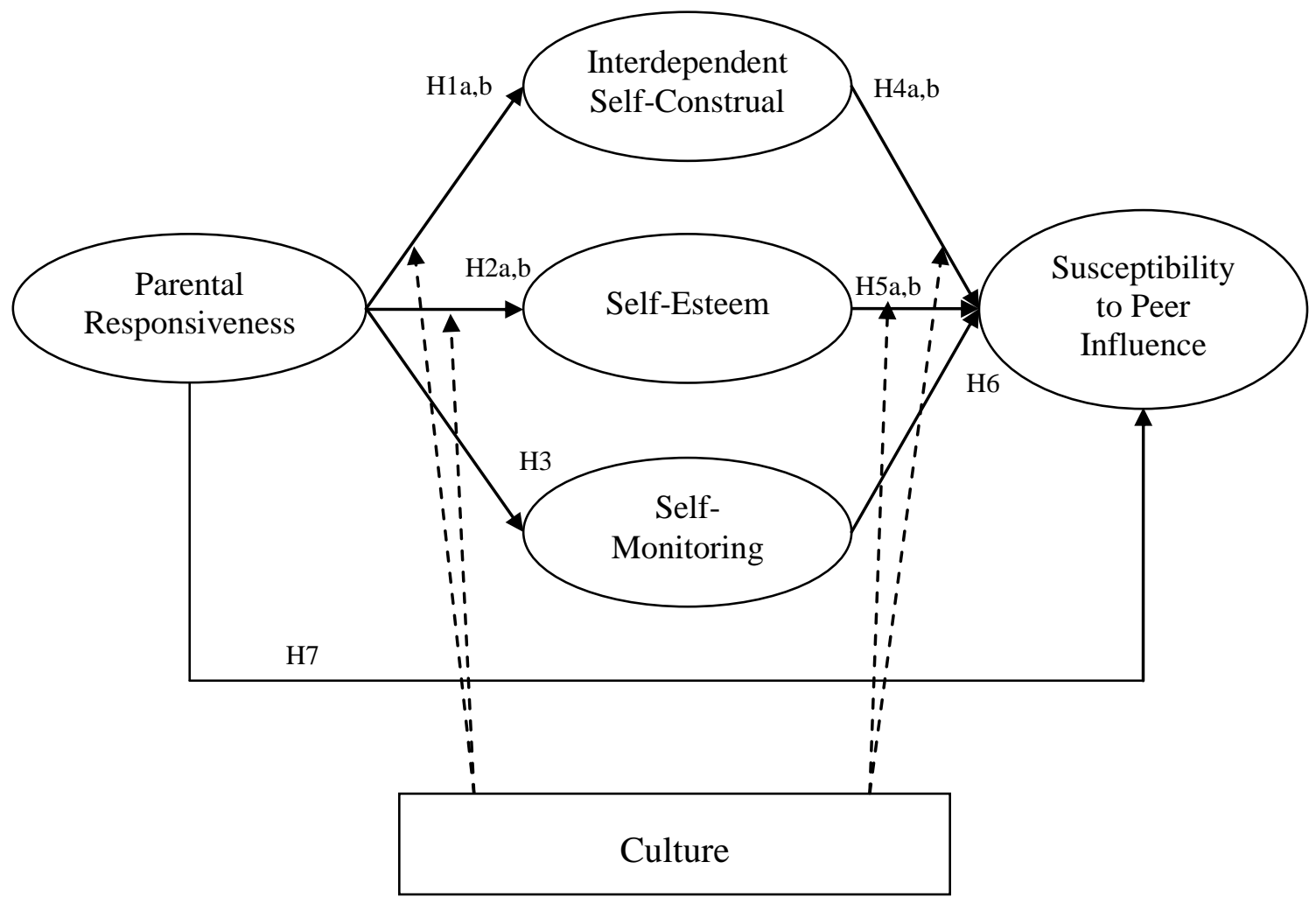

